\title{
EGFR gene amplification is relatively common and associates with outcome in intestinal adenocarcinoma of the stomach, gastro-oesophageal junction and distal oesophagus
}

Eva-Maria Birkman ${ }^{1 *}$, Annika Ålgars $^{2,3}$, Minnamaija Lintunen ${ }^{1}$, Raija Ristamäki ${ }^{2}$, Jari Sundström ${ }^{1}$ and Olli Carpén ${ }^{1,4}$

\begin{abstract}
Background: Approximately 50 \% of gastric adenocarcinomas belong to a molecular subgroup characterised by chromosomal instability and a strong association with the intestinal histological subtype. This subgroup typically contains alterations in the receptor tyrosine kinase-RAS pathway, for example EGFR or HER2 gene amplifications leading to protein overexpression. In clinical practice, HER2 overexpressing metastatic gastric cancer is known to respond to treatment with anti-HER2 antibodies. By contrast, anti-EGFR antibodies have not been able to provide survival benefit in clinical trials, which, however, have not included patient selection based on the histological subtype or EGFR gene copy number analysis of the tumours. To examine the role of EGFR as a potential biomarker, we studied the prevalence, clinicopathological associations as well as prognostic role of EGFR and HER2 expression and gene amplification in intestinal adenocarcinomas of the stomach, gastro-oesophageal junction and distal oesophagus.
\end{abstract}

Methods: Tissue samples from 220 patients were analysed with EGFR and HER2 immunohistochemistry. Those samples with moderate/strong staining intensity were further analysed with silver in situ hybridization to quantify gene copy numbers. The results were associated with clinical patient characteristics and survival.

Results: Moderate/strong EGFR protein expression was found in 72/220 (32.7 \%) and EGFR gene amplification in 31/220 (14.1\%) of the tumours, while moderate/strong HER2 protein expression was detected in 31/220 (14.1\%) and HER2 gene amplification in 29/220 (13.2\%) of the tumours. EGFR and HER2 genes were co-amplified in eight tumours (3.6\%). EGFR gene amplification was more common in tumours of distal oesophagus/gastro-oesophageal junction/cardia than in those of gastric corpus $(p=0.013)$. It was associated with shortened time to cancer recurrence $(p=0.026)$ and cancer specific survival $(p=0.033)$.

Conclusions: EGFR gene amplification is relatively common in intestinal adenocarcinomas and associates with decreased survival. It is rarely concurrent with HER2 gene amplification, suggesting that anti-EGFR therapies might be applicable to some patients not eligible for anti-HER2 treatment. Analogous to HER2 testing, determination of EGFR gene amplification status in concert with immunohistochemistry could improve the specificity of patient selection when investigating the possible benefits of anti-EGFR therapies in the treatment of gastric adenocarcinomas.

Keywords: EGFR, HER2, Silver in situ hybridization, Gene amplification, Gastric cancer

\footnotetext{
*Correspondence: emabir@utu.fi

'Department of Pathology, University of Turku and Turku University Hospital,

TYKS-SAPA, Turku, Finland

Full list of author information is available at the end of the article
} 


\section{Background}

EGFR (ERBB1) and HER2 (ERBB2) are members of a tyrosine kinase receptor family frequently activated in cancer either by receptor overexpression or mutations. Metastatic HER2 overexpressing gastric or gastrooesophageal junction (GOJ) adenocarcinomas can be treated with monoclonal anti-HER2 antibodies in combination with chemotherapy and the only targeted first-line antibody therapy for these tumours is trastuzumab. In contrast, monoclonal anti-EGFR antibodies are currently not indicated for the treatment of gastric cancer, although they are used for patients with metastatic colorectal or head and neck carcinomas.

Gastric adenocarcinomas are traditionally divided into intestinal and diffuse histological subtypes by Laurén classification [1]. Interestingly, it was recently suggested that these tumours can be classified into four distinct molecular subgroups based on their genomic alterations. One of the subgroups, characterised by chromosomal instability (CIN), accounts for about $50 \%$ of gastric cancers and is strongly associated with the intestinal histological subtype and GOJ/cardiac location. Typical alterations in the CIN subtype include TP53 gene aberrations and activation of the receptor tyrosine kinase-RAS pathway, for example by receptor tyrosine kinase gene amplifications. In contrast, diffuse-type tumours are concentrated in a separate subgroup associating with overall genomic stability as well as distinctive genetic changes affecting cell adhesion and motility [2].

While anti-EGFR antibody treatment is beneficial in colorectal cancer [3, 4], no survival benefit has been observed in phase III clinical trials on gastric and gastrooesophageal cancer for patients treated with anti-EGFR antibody-chemotherapy combination compared with patients treated with chemotherapy alone $[5,6]$. Importantly, however, these studies included no patient selection based on the histological subtype of the tumours, EGFR protein expression or EGFR gene copy number (GCN) analysis. As demonstrated in the case of anti-HER2 therapy, an appropriate preselection with an easily applicable biomarker test might increase the potential to identify those patients who could benefit from anti-EGFR therapy.

In this study, we focused on intestinal adenocarcinomas in three locations: the stomach, gastro-oesophageal junction and distal oesophagus. Our aim was to examine the prevalence, clinicopathological associations as well as prognostic role of EGFR and HER2 protein expression and gene amplification in these tumours. First, we analysed EGFR and HER2 alterations by using immunohistochemistry (IHC) to select the tumours with moderate/strong expression of EGFR or HER2 protein. Second, we performed EGFR or HER2 silver in situ hybridisation (SISH) in selected cases to quantify GCNs. The validity of this algorithm for EGFR gene has previously been demonstrated with colorectal adenocarcinomas $[7,8]$ and was confirmed in this study by a set of control samples with negative or weak IHC staining.

\section{Methods}

\section{Patients and clinical tumour material}

The study population in this retrospective study consists of 220 patients diagnosed with intestinal adenocarcinoma of the stomach, gastro-oesophageal junction or distal oesophagus at the Turku University Hospital between the years 1993 and 2012. Initially, we used the clinical database of Auria Biobank (see below) to find all patients with the diagnosis of adenocarcinoma of the stomach, gastrooesophageal junction or distal oesophagus $(n=437)$. The original histopathological information regarding these samples was then obtained to compile a preliminary list of patients, and the respective histological slides were retrieved from the archive. The exclusion criteria for this study were: diffuse or neuroendocrine histological subtype $(n=155)$, metastatic adenocarcinoma from a different organ $(n=6)$, intramucosal carcinoma (Tis) $(n=23)$ and insufficient sample material $(n=33)$. All cases were reanalysed by an expert gastrointestinal pathologist and the intestinal histological subtype of the tumours was confirmed by the presence of well-defined glandular structures in accordance with the Laurén classification [1]. Primarily, tissue samples from primary surgical specimens were included. In order to attain a comprehensive study population, representative biopsies were used in case of 22 patients (10\%): four (1.8\%) patients were not operated due to stage IV disease at the time of diagnosis and 18 $(8.2 \%)$ patients had received perioperative chemoradiotherapy resulting in insufficient surgical material for immunohistochemical analysis. The type of surgery was total gastrectomy for 120 (54.5\%) patients, subtotal gastrectomy or tumour resection for 79 (35.9\%) patients and palliative surgery for 17 (7.7 \%) patients. The residual tumour classification was determined as R0 (no residual tumour) for 167 (75.9\%) patients, R1 (microscopic residual tumour) for 24 (10.9\%) patients and R2 (macroscopic residual) for $17(7.7 \%)$ patients. The residual tumour status could not be determined for 12 (5.5\%) patients. The median follow-up time for all patients was 10.5 years. The patient characteristics are presented in Table 1.

Tumour stage was assessed according to the current WHO Classification manual [9]. The study was conducted in accordance with the Declaration of Helsinki and the Finnish legislation for the use of archived tissue specimens and associated clinical information. The clinical data were retrieved, and the histological samples were collected and analysed with the endorsement of the National Authority for Medico-Legal Affairs and The Ethics Committee of the Hospital District of Southwest Finland as well as with the permission of Auria Biobank 
Table 1 Patient characteristics

\begin{tabular}{|c|c|c|c|}
\hline & Female, N (\%) & Male, N (\%) & All, N (\%) \\
\hline Number of patients & 79 (35.9) & $141(64.1)$ & 220 \\
\hline \multicolumn{4}{|l|}{ Age at diagnosis (years) } \\
\hline Median & 77 & 72 & 74 \\
\hline Range & $33-93$ & $43-90$ & $33-93$ \\
\hline \multicolumn{4}{|l|}{ Site of primary tumour } \\
\hline Distal oesophagus & $4(5.1)$ & $16(11.3)$ & $20(9.1)$ \\
\hline GOJ/cardia & $17(21.5)$ & $46(32.6)$ & $63(28.6)$ \\
\hline Corpus & $21(26.6)$ & $44(31.2)$ & $65(29.5)$ \\
\hline Antrum/pylorus & $37(46.8)$ & $35(24.8)$ & $72(32.7)$ \\
\hline \multicolumn{4}{|l|}{ Tumour differentiation grade } \\
\hline Grade 1 & $14(17.7)$ & $16(11.3)$ & $30(13.6)$ \\
\hline Grade 2 & $33(41.8)$ & 70 (49.6) & $103(46.8)$ \\
\hline Grade 3 & $32(40.5)$ & $55(39.0)$ & 87 (39.5) \\
\hline \multicolumn{4}{|l|}{ Stage at diagnosis } \\
\hline IA & $15(19.0)$ & $18(12.8)$ & $33(15.0)$ \\
\hline $\mathrm{IB}$ & $7(8.9)$ & 19 (13.5) & $26(11.8)$ \\
\hline$\| \mathrm{A}$ & $17(21.5)$ & $33(23.4)$ & $50(22.7)$ \\
\hline$\| B$ & $14(17.7)$ & $19(13.5)$ & $33(15.0)$ \\
\hline$\| \mathrm{A}$ & $7(8.9)$ & $21(14.9)$ & $28(12.7)$ \\
\hline$\| I B$ & $11(13.9)$ & $19(13.5)$ & $30(13.6)$ \\
\hline$\| I I C$ & $1(1.3)$ & $5(3.5)$ & $6(2.7)$ \\
\hline IV & $7(8.9)$ & $7(5.0)$ & $14(6.4)$ \\
\hline \multicolumn{4}{|l|}{ Residual tumour classification } \\
\hline RO (no residual tumour) & $62(78.5)$ & $105(74.5)$ & $167(75.9)$ \\
\hline R1 (microscopic residual tumour) & $5(6.3)$ & $19(13.5)$ & $24(10.9)$ \\
\hline R2 (macroscopic residual tumour) & $8(10.1)$ & $9(6.4)$ & $17(7.7)$ \\
\hline Rx (unknown) & $4(5.1)$ & $8(5.7)$ & $12(5.5)$ \\
\hline \multicolumn{4}{|c|}{ Perioperative and adjuvant therapy ${ }^{a}(N=206)$} \\
\hline Only chemotherapy & $7(9.7)$ & $24(17.9)$ & $31(15.0)$ \\
\hline Chemoradiotherapy & $4(5.6)$ & $16(11.9)$ & $20(9.7)$ \\
\hline Only radiation therapy & $1(1.4)$ & $4(3.0)$ & $5(2.4)$ \\
\hline No adjuvant therapy & $58(80.6)$ & $89(66.4)$ & $147(71.4)$ \\
\hline Unknown & $2(2.8)$ & $1(0.7)$ & $3(1.5)$ \\
\hline \multicolumn{4}{|l|}{ Tumour recurrence $(N=195)$} \\
\hline No recurrence & $55(79.7)$ & $82(65.1)$ & $137(70.3)$ \\
\hline Single metastasis $>6$ months & $10(14.5)$ & $26(20.6)$ & $36(18.5)$ \\
\hline Multiple metastases $>6$ months & $4(5.8)$ & $18(14.3)$ & $22(11.3)$ \\
\hline \multicolumn{4}{|l|}{ Follow-up status } \\
\hline Alive and free of disease & $22(27.8)$ & $31(22.0)$ & $53(24.1)$ \\
\hline Alive with disease & $1(1.3)$ & $1(0.7)$ & $2(0.9)$ \\
\hline Died of disease & $43(54.4)$ & $74(52.5)$ & $117(53.2)$ \\
\hline Died of other cause & $12(15.2)$ & $30(21.3)$ & $42(19.1)$ \\
\hline Unknown cause of death & $1(1.3)$ & $5(3.5)$ & $6(2.7)$ \\
\hline
\end{tabular}


hosting the specimen archive. All the specimens were from Auria biobank, which has obtained its archived diagnostic sample collection with an opt-out procedure according to the Finnish biobank act [10]. Biobanks authorized and inspected by National Supervisory Authority for Welfare and Health can provide human specimens collected during diagnostic procedures and associated clinical information for research purposes based on the biobank's scientific board review. Thus, informed consent from surviving patients was not required.

\section{Procedures}

For each tumour, the most representative formalin-fixed paraffin-embedded (FFPE) tissue block was chosen and new sections were cut for both IHC staining and SISH. The methods for EGFR IHC and EGFR SISH have been described previously [7], and HER2 IHC was performed similarly with monoclonal HER2 antibody (clone 4B5, Ventana Medical Systems/Roche Diagnostics, Tucson, AZ, USA). HER2/Chr17 double-SISH was detected with HER2 DNA Probe and INFORM Chromosome 17 Probe (Ventana/Roche) and performed with ultraView SISH Detection Kit and ultraView Alkaline Phosphatase (AP) Red ISH Detection Kit (Ventana/Roche).

\section{Immunohistochemistry and silver in situ hybridization}

With EGFR, tumour scoring was based on the most intense membranous or membranous + cytoplasmic staining (0, negative; $1+$, weak; $2+$, moderate; $3+$, strong). Strong staining was seen as intense reaction with $5 \mathrm{x}$ objective magnification, moderate staining was clearly identified with $5 \mathrm{x}$ objective magnification and weak staining was identified only with $10 x$ objective magnification. Specimens were classified as IHC high if showing $2+$ or $3+$ membranous or membranous + cytoplasmic staining intensity in $\geq 10 \%$ of tumour cells in surgical specimens or in $\geq 5$ clustered tumour cells in biopsies. These IHC high samples were further analysed with SISH. This algorithm is based on our previous observation that high EGFR IHC staining intensity positively correlates with increased EGFR GCN [7]. With HER2 IHC, tumours were scored according to standard criteria [11, 12] and specimens showing $2+$ or $3+$ membranous staining in $\geq 10 \%$ of tumour cells or in $\geq 5$ clustered tumour cells in biopsies were classified as IHC high and analysed with SISH. EGFR and HER2 IHC and GCN were scored independently by two observers (EB and JS) without knowledge of the clinical information. Consensus scoring was used in case of differing individual results.

EGFR was quantified from the areas of high EGFR IHC intensity as described previously [7, 8]. Forty tumour cells with the highest number of copies were analysed from the EGFR SISH slides and an average value was calculated for each surgical sample. If these forty cells contained numerous overlapping EGFR SISH signals (clusters), the tumour was determined to have EGFR gene amplification. In biopsies, a group of $\geq 5$ tumours cells with gene clusters was considered as amplification. One EGFR cluster was approximated to contain $\geq 10$ gene copies. HER2 GCN was detected with chromosome 17 (Chr-17) number (number of copies of chromosome per cell) and the HER2/Chr-17 ratio was assessed according to standard criteria [13]. If HER2 gene clusters were detected in $\geq 10 \%$ of tumour cells in surgical specimens or in a group of $\geq 5$ tumour cells in biopsies, the tumour was determined to contain HER2 gene amplification. One HER2 cluster was counted as $\geq 6$ gene copies. To validate our method of including only tumours with high EGFR IHC intensity for EGFR SISH, we assessed EGFR GCN in fifteen randomly selected tumours in which EGFR IHC was scored as negative/ weak. No EGFR amplification was found in these tumours (GCN 2.1-3.3).

\section{Statistical analysis}

Statistical analyses were performed with IBM SPSS Statistics for Windows, version 21.0 (IBM Corporation, Armonk, NY). Frequency table data were analysed using the $\chi^{2}$ test, either with the Pearson $\chi^{2}$ test or Fisher's exact test for categorical variables. $2 \times 2$ tables were used to calculate odds ratios (OR). Kaplan-Meier method and log-rank test as well as Cox's proportional hazards regression model were used for univariate survival analysis. Multivariate survival analysis was performed by Cox's proportional hazards regression model. Variables with a $p$-value under 0.2 in univariate analysis were included in the multivariate analyses. Time to recurrence (TTR) was calculated from the time of diagnosis to the time of first recurrence, death of primary cancer or to the last follow-up date. Only recurrences occurring $\geq 6$ months after diagnosis were considered relevant. Earlier detection of a local or distant recurrence was considered likely to present an initially advanced disease. Patients treated with surgery or surgery and adjuvant therapy without disease recurrence $\geq 6$ months after diagnosis were considered curatively treated. Cancer-specific survival (CSS) was calculated from the time of diagnosis to the time of death of primary cancer or the last follow-up date and overall survival (OS) from the time of diagnosis to the time of death of any cause or the last follow-up date. Five patients $(2.3 \%)$ who had received trastuzumab treatment for recurrent cancer were excluded from the CSS and OS analyses and additionally 14 patients with stage IV disease $(6.4 \%)$ from the TTR analysis. All statistical tests were two-sided and p-values under 0.05 were considered statistically significant. 


\section{Results}

\section{EGFR and HER2 immunohistochemical staining}

All 220 tumour samples were analysed with EGFR and HER2 IHC. High membranous or membranous + cytoplasmic EGFR IHC staining intensity $(2+/ 3+)$ was observed in $72(32.7 \%)$ of the tumours, while $2+/ 3+$ HER2 IHC staining intensity was present in $31(14.1 \%)$ tumours. Among these, concurrent high IHC staining intensity of EGFR and HER2 was detected in 14 (6.4 \%) tumours. The results from EGFR and HER2 IHC stainings are shown in Table 2.

\section{EGFR and HER2 silver in situ hybridisation}

Gene copy numbers were analysed with EGFR or HER2 SISH in all tumours with high EGFR or HER2 IHC staining intensity. EGFR gene amplification was found in $31 / 72$ tumours ( $14.1 \%$ of the whole study material) and HER2 gene amplification in 29/31 tumours (13.2\% of the whole study material). Among these, EGFR and HER2 co-amplification was detected in 8/14 tumours (3.6\% of the whole study material). EGFR and HER2 gene amplification status was significantly concordant in antrum (Fisher's exact test, $p=0.004$ ). The results from EGFR and HER2 SISH stainings according to anatomical location are presented in Table 3. There was marked intratumoural heterogeneity of EGFR and HER2 gene amplification, as shown in Figs. 1 and 2 .

\section{EGFR and HER2 protein expression and gene}

\section{amplification in relation to clinicopathological variables}

Evaluated by IHC staining intensity, moderate or strong EGFR protein expression was associated with the depth of tumour invasion (pT3-pT4 versus pT1-pT2; Fisher's exact test, $p=0.029$ ); OR 2.15, $95 \%$ CI: 1.11-4.17), but did not associate with tumour location (distal oesophagus/ GOJ/cardia versus gastric corpus/antrum/pylorus; Fisher's exact test, $p=0.054)$. In contrast, no significant association was found between HER2 protein expression levels and the depth of tumour invasion or tumour location. No significant association was observed between EGFR or HER2 protein expression levels and patient gender, tumour stage or histological differentiation grade.

EGFR gene amplification was associated with deep invasion (pT3-pT4 versus pT1-pT2; Fisher's exact test, $p=0.020$; OR 3.49, $95 \%$ CI: 1.17-10.4) and it was more commonly detected in stage III-IV tumours than in stage I-II tumours (Fisher's exact test, $p=0.024$; OR 2.55, 95 \% CI: 1.18-5.51). Additionally, EGFR gene amplification was more common in tumours of distal oesophagus (5/20 tumours, $25.0 \%$ ) and GOJ/cardia $(13 / 63$ tumours, $20.6 \%)$ than in those of gastric corpus (2/65 tumours, $3.1 \%)\left(\chi^{2}, p=0.013\right)$. This distribution pattern was also seen in male patients $\left(\chi^{2}, p=0.034\right)$ but not in female patients. When tumour location was considered as a dichotomous variable, EGFR gene amplification was still more common in proximally located tumours (distal oesophagus/GOJ/cardia versus gastric corpus/antrum/pylorus; (Fisher's exact test, $p=0.016$ ); OR 2.64, 95 \% CI: 1.22-5.73). When analysed separately for males and females, the association between EGFR gene amplification and proximal tumours was significant in males (Fisher's exact test, $p=0.011$; OR 3.58, $95 \% \mathrm{CI}: 1.37-9.36)$ but not in females. In contrast, HER2 gene amplification status was not significantly associated with the depth of tumour invasion, tumour stage or tumour location. No significant association was found between EGFR or HER2 gene amplification status and patient gender, age at diagnosis or histological differentiation grade of the tumour. The association between EGFR and HER2 protein expression as well as gene amplification and different clinicopathological variables are presented in Table 4 .

\section{EGFR and HER2 gene amplification in relation to survival}

In univariate survival analysis, EGFR gene amplification was associated with shortened time to recurrence (TTR, median) (22 vs. 57 months, log-rank test, $p=0.026$; Cox test, $p=0.028$, HR: 1.73 , $95 \% \mathrm{CI}: 1.06-2.83)$ and with shortened cancer-specific survival (CSS, median) (29 vs. 57 months, log-rank test, $p=0.033$; Cox test, $p=0.035$, HR: 1.67, 95 \% CI: 1.04-2.69) (Fig. 3). Median TTR and CSS of the patients were both 45 months. HER2 gene amplification was not significantly associated with TTR, but patients with HER2 gene amplification had a notably lower median CSS of 22 months than patients without HER2 amplification (46 months). However, the difference was not statistically significant (log-rank test, $p=$ 0.256) (Fig. 3).

In univariate analysis, increasing depth of tumour invasion was associated with decreased TTR and CSS

Table 2 Intensity of EGFR and HER2 immunohistochemical stainings in intestinal adenocarcinomas ${ }^{\mathrm{a}}(N=220)$

\begin{tabular}{llll}
\hline IHC staining intensity & EGFR, N (\%) $)^{\mathrm{a}}$ & HER2, N (\%) $)^{\mathrm{b}}$ & EGFR and HER2, N (\%) \\
\hline $0 / 1+$ & $148(67.3)$ & $189(85.9)$ & $131(59.5)$ \\
$2+/ 3+$ & $72(32.7)$ & $31(14.1)$ & $14(6.4)$ \\
\hline
\end{tabular}

IHC immunohistochemistry. 0 , negative; $1+$ low; $2+$ moderate; $3+$ strong

${ }^{a}$ According to the most intense membranous or membranous + cytoplasmic staining

${ }^{\mathrm{b}}$ According to the most intense membranous staining

${ }^{\mathrm{c} C o n c o r d a n t}$ IHC staining intensity. In 75 tumours (34.1\%) IHC staining intensity was discordant 
Table 3 EGFR and HER2 silver in situ hybridization in intestinal-type adenocarcinomas according to anatomical location

\begin{tabular}{|c|c|c|c|c|c|c|}
\hline \multirow[t]{2}{*}{ Gene copy number status } & Distal oesophagus & GOJ/cardia & Corpus & Antrum/pylorus & Total & $P$ value \\
\hline & $N=20(\%)$ & $N=63(\%)$ & $N=65(\%)$ & $N=72(\%)$ & $N=220(\%)$ & $\left(x^{2} \text { test }\right)^{c}$ \\
\hline \multicolumn{7}{|l|}{ EGFR amplification ${ }^{a}$} \\
\hline Yes & $5(16.1)$ & $13(41.9)$ & $2(6.5)$ & $11(35.5)$ & $31(100.0)$ & \multirow[t]{3}{*}{$0.013^{d}$} \\
\hline No & $15(7.9)$ & $50(26.5)$ & $63(33.3)$ & $61(32.3)$ & $189(100.0)$ & \\
\hline Total N of amplification (\%) & $5 / 20(25.0)$ & 13/63 (20.6) & 2/65 (3.1) & $11 / 72(15.3)$ & $31 / 220(14.1)$ & \\
\hline \multicolumn{7}{|l|}{ HER2 amplification ${ }^{a}$} \\
\hline Yes & $5(17.2)$ & $9(31.0)$ & $9(31.0)$ & $6(20.7)$ & $29(100.0)$ & \multirow[t]{3}{*}{ NS } \\
\hline No & $15(7.9)$ & $54(28.3)$ & $56(29.3)$ & $66(34.6)$ & $191(100.0)$ & \\
\hline Total N of amplification (\%) & $5 / 20(25.0)$ & 9/63 (14.3) & 9/65 (13.8) & $6 / 72(8.3)$ & 29/220 (13.2) & \\
\hline \multicolumn{7}{|l|}{ EGFR and HER2 co-amplification ${ }^{a}$} \\
\hline Yes & $2(25.0)$ & $1(12.5)$ & $1(12.5)$ & $4(50.0)$ & $8(100.0)$ & \multirow[t]{3}{*}{ NS } \\
\hline No & $18(8.5)$ & $62(29.2)$ & $64(30.2)$ & $68(32.1)$ & $212(100.0)$ & \\
\hline Total N of co-amplification (\%) & $2 / 20(10.0)$ & 1/63 (1.6) & $1 / 65(1.5)$ & 4/72 (5.6) & $8 / 220(3.6)$ & \\
\hline$P$ value (Fisher's exact test $)^{b}$ & NS & NS & NS & $0.004^{d}$ & & \\
\hline
\end{tabular}

IHC immunohistochemistry, GOJ gastro-oesophageal junction, GCN gene copy number, NS not significant

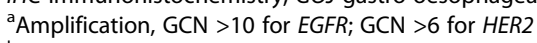

${ }^{b}$ Concordant vs. discordant EGFR and HER2 amplification status

'Distal oesophagus, GOJ and cardia vs. corpus

${ }^{\mathrm{d}}$ Statistically significant

(TTR: log-rank test, $p<0.0001$; Cox test, $p<0.0001$, HR 1.46, $95 \%$ CI: $1.19-1.80$ and CSS: log-rank test, $p<$ 0.0001; Cox test, $p<0.0001$, HR 1.60, 95 \% CI: 1.30-1.96). Similarly, increasing tumour stage was associated with decreased TTR and CSS (TTR: log-rank test, $p=0.005$; Cox test, $p=0.001$, HR 1.52, $95 \%$ CI: $1.18-1.96$ and CSS: logrank test, $p<0.0001$; Cox test $p<0.0001$, HR 1.94, $95 \%$ CI: 1.53-2.45). In addition, increasing patient age at the time of diagnosis was associated with shorter CSS (Cox test, $p=0.048$, HR 1.02, $95 \% \mathrm{CI}: 1.00-1.04)$, but not with TTR (Cox test, $p=0.341$ ). No significant association was found between patient gender (log-rank test, TTR: $p=0.372$; CSS: $p=0.818$ ) or tumour location (log-rank test, TTR: $p=0.057$; CSS: $p=0.262$ ). In Kaplan-Meier analysis, histological differentiation grade was not associated with survival (grade I versus II versus III; log-rank test, TTR: $p=0.118$; CSS: $p=0.053)$. However, when analysed separately grade II tumours were associated with shorter TTR in comparison to grade I tumours (univariate Cox test, $p=0.043$, HR 1.95, 95 \% CI: 1.02-3.74). Additionally, grade II and III tumours were associated with shorter CSS in comparison to grade I tumours (univariate Cox test, grade II: $p=0.020$, HR 2.22, $95 \%$ CI: 1.13-4.36; grade III: $p=0.029$, HR 2.15, $95 \% \mathrm{CI}: 1.08-4.27)$. No significant association was observed between EGFR or HER2 gene amplification status and overall survival (OS). EGFR or HER2 protein expression, evaluated by IHC staining intensity, was not significantly associated with TTR, CSS or OS.

In the multivariate model for TTR, EGFR gene amplification was analysed together with tumour stage, histological differentiation grade and tumour location. In the multivariate analysis for CSS, EGFR gene amplification was analysed together with tumour stage, histological differentiation grade and patient age at the time of diagnosis. Tumour stage remained as a single predictive factor for TTR (Cox test, stage III: $p=0.014$, HR 2.05, 95 \% CI: 1.16-3.63) as well as for CSS (Cox test, stage III: $p=0.023$, HR 1.99, 95 \% CI: 1.10-3.61; stage IV: $p<0.0001$, HR 11.4, 95 \% CI: 5.34-24.4). The results from univariate and multivariate survival analyses are presented in Table 5.

\section{Discussion}

This study shows that EGFR gene amplification is not uncommon in intestinal adenocarcinoma of the stomach, gastro-oesophageal junction and distal oesophagus. In addition, we demonstrate that EGFR amplification is most prevalent in proximally located tumours and significantly associated with decreased survival, as defined by TTR and CSS.

In previous studies, EGFR gene amplification has been reported to be present in only $2.3-4.9 \%$ of gastric cancers including all histological subtypes [14-16], whereas the reported numbers for HER2 gene amplification vary between 7 and $17 \%[17,18]$. The prevalence of EGFR and HER2 co-amplification has been reported as low $(<0.5 \%)[15,16]$, albeit studies analysing concurrent EGFR and HER2 GCN changes are few and none have been carried out after the novel molecular subtypes of gastric cancer were published [2]. In contrast, we found EGFR gene amplification in $14.4 \%$ and receptor coamplification in $3.6 \%$ of intestinal adenocarcinomas. 


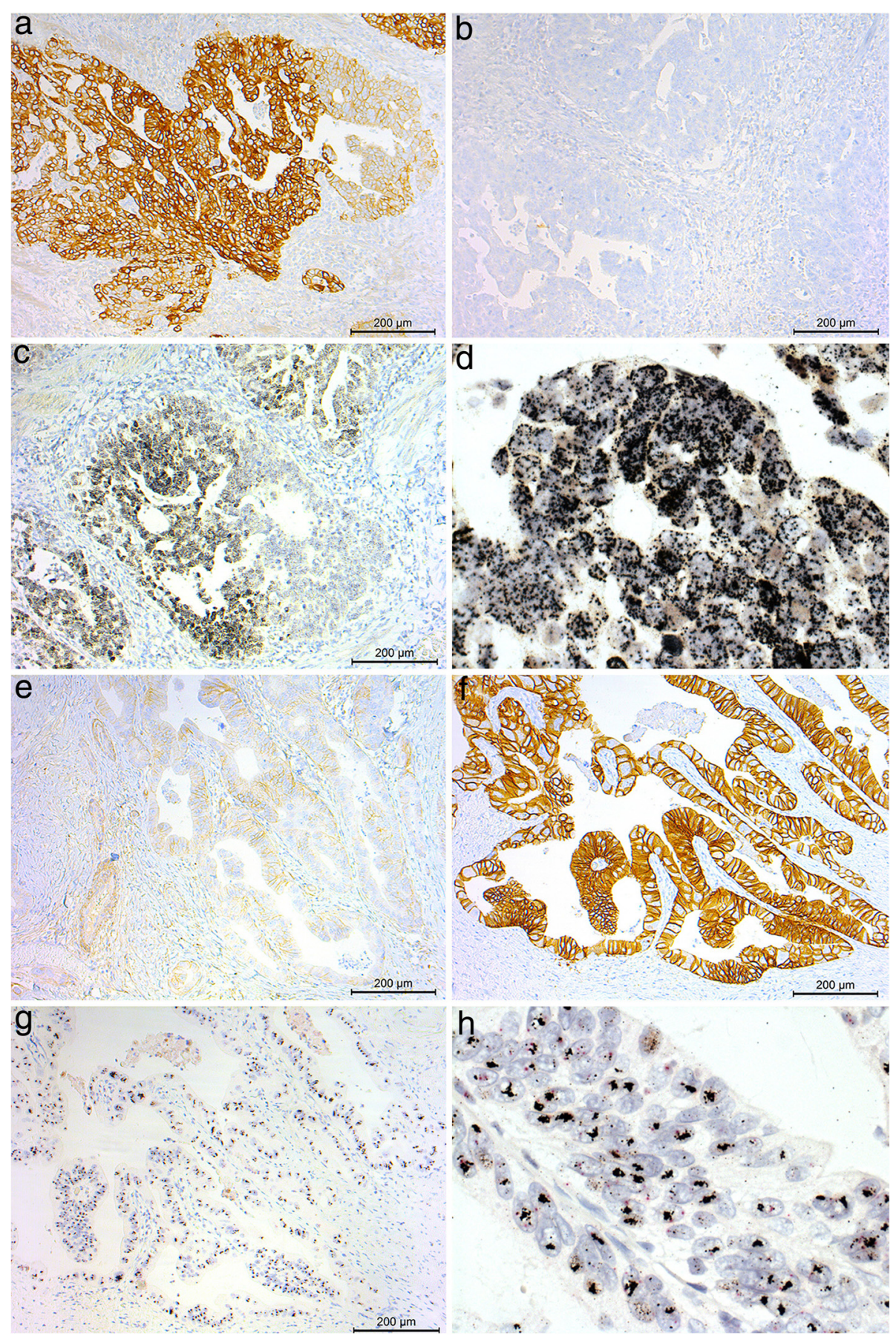

Fig. 1 The association between EGFR/HER2 protein expression and EGFR/HER2 gene amplification in two intestinal-type oesophagogastric adenocarcinomas. Figures a-d show the same area in a single tumour: a Strong (3+) membranous EGFR protein expression (IHC), b negative HER2 protein expression and $\mathbf{c}-\mathbf{d}$ EGFR gene amplification (SISH). Figures $\mathbf{e}-\mathbf{h}$ show the same area in another tumour: e Negative EGFR protein expression $(\mathrm{IHC})$, (f) strong (3+) membranous HER2 protein expression and $\mathbf{g}-\mathbf{h}$ HER2 gene amplification (SISH). Original objective magnification 10x and 60x. IHC, immunohistochemistry; SISH, silver in situ hybridisation

HER2 has been found to be overexpressed, as determined by both IHC and GCN analyses, in 7-25\% of gastric adenocarcinomas [11, 12, 17, 19] including all histological subtypes, which is comparable with our finding that high
HER2 protein expression was found in $14.1 \%$ and $H E R 2$ gene amplification in $13.2 \%$ of intestinal adenocarcinomas.

Recent molecular classification studies have linked approximately $36-50 \%$ of gastric adenocarcinomas 


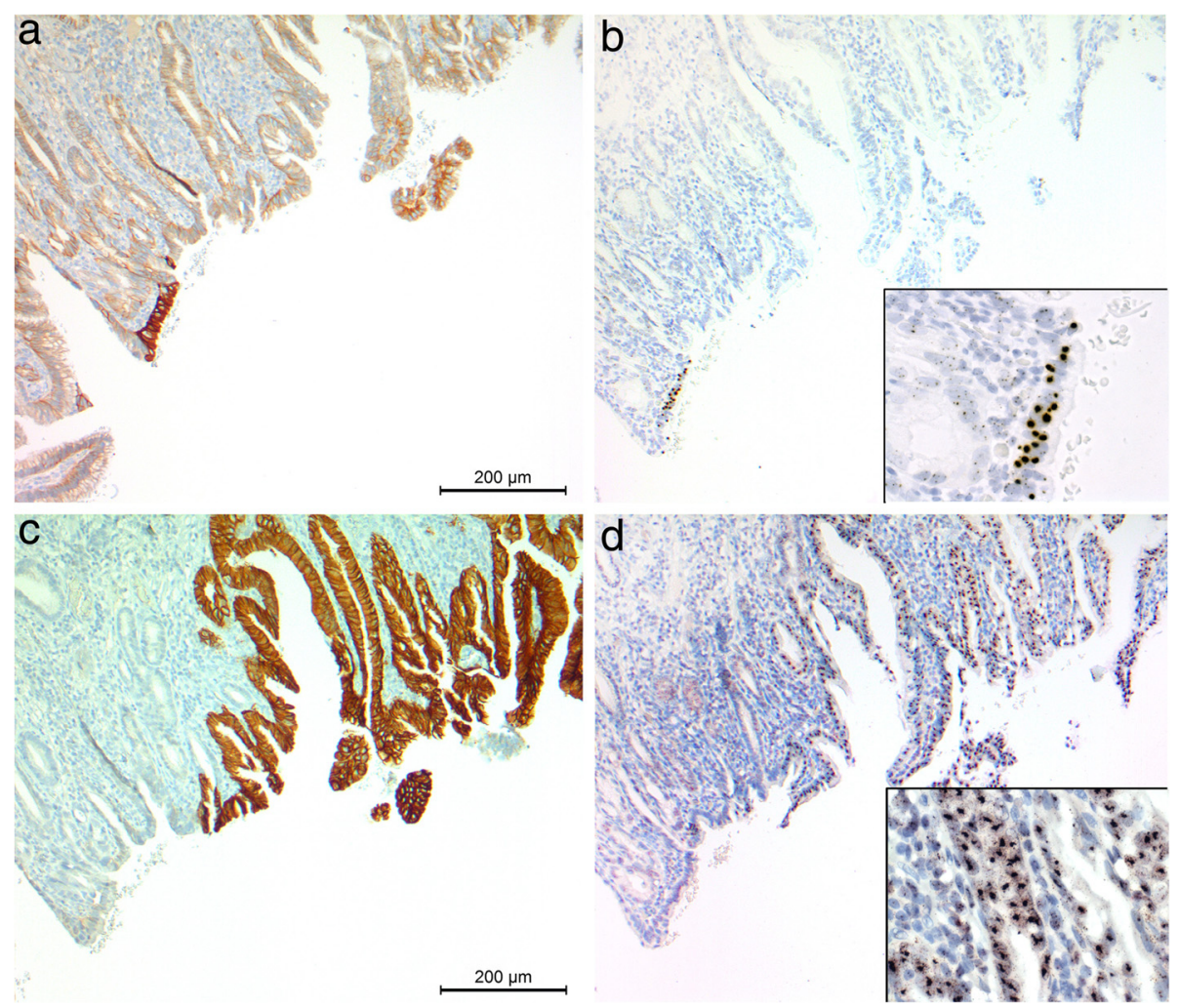

Fig. 2 The association between strong EGFR/HER2 protein expression and EGFR/HER2 gene amplification in a single intestinal-type oesophagogastric adenocarcinoma (original objective magnification 10x). All images are from the same area of the tumour. a Strong (3+) EGFR protein expression (IHC). b EGFR gene amplification (SISH). c Strong (3+) HER2 protein expression (IHC). d HER2 gene amplification (SISH). Insets show the gene amplification (original objective magnification 60x). Note that EGFR and HER2 are not amplified in the same cancer cells but in adjacent areas. IHC, immunohistochemistry; SISH, silver in situ hybridisation

with characteristics such as intestinal-type histology, chromosomal abnormalities, changes in the receptor tyrosine kinase-RAS signaling pathway, as well as TP53 gene and somatic copy-number aberrations. These characteristics have been associated with a distinct molecular subgroup: tumours in the CIN subgroup are characterised by chromosomal instability, while the MSS/TP53- ${ }^{-}$subgroup typically contains microsatellite stable tumours with inactive TP53 [2, 20]. Both of these studies could further show that histologically diffusetype tumours are concentrated in a separate subgroup with molecular characteristics different from those defining CIN or MSS/TP53-. However, the predominant anatomical location of tumours belonging to either CIN or MSS/TP53- ${ }^{-}$subgroup was found to differ: CIN tumours were mostly located in GOJ/cardia, whereas MSS/TP53- tumours were predominantly situated in gastric antrum $[2,20]$. It has been previously demonstrated that HER2 gene amplification is strongly associated with the intestinal histological subtype, as compared to the diffuse subtype, as well as with the gastro-oesophageal location of tumours $[17,19]$. In our material, EGFR gene amplification was most common in the tumours of distal oesophagus and GOJ/cardia, as observed in the CIN subgroup, but infrequent in the tumours of gastric corpus. In antral/pyloric tumours, the observed prevalence of EGFR gene amplification was intermediate to that in other locations.

EGFR gene amplification was found to be significantly associated with decreased TTR and CSS, which is consistent with earlier findings of association between EGFR gene amplification and survival [14, 15]. Results from these studies are, however, based on notably smaller sample size and/or histologically more heterogeneous tumour material than included in this present study. There are contradictory reports regarding the relevance of HER2 gene amplification as a negative prognostic factor in gastric cancer $[15,17]$. In this study, the non-significant association may partly be related to including only intestinal adenocarcinomas in the study material.

HER2 overexpression is known to predict treatment benefit from anti-HER2 antibody therapy. The survival of patients is significantly improved in metastatic gastric and gastro-oesophageal cancer by the addition of trastuzumab to a cisplatin-fluoropyrimidine-containing chemotherapy regimen [12], whereas no survival benefit has been 
Table 4 Association between the clinicopathological variables and EGFR/HER2 protein expression or gene amplification ( $N=220)$

\begin{tabular}{|c|c|c|c|c|c|c|c|c|c|c|c|c|}
\hline & \multicolumn{3}{|c|}{ EGFR IHC staining intensity, $N(\%)$} & \multicolumn{3}{|c|}{ EGFR in situ hybridisation status, $N(\%)$} & \multicolumn{3}{|c|}{ HER2 IHC staining intensity, N (\%) } & \multicolumn{3}{|c|}{ HER2 in situ hybridisation status, $N(\%)$} \\
\hline & $0 / 1+$ & $2+/ 3+$ & $P$ value $^{a}$ & $\begin{array}{l}\text { EGFR gene } \\
\text { amplification }\end{array}$ & $\begin{array}{l}\text { No EGFR gene } \\
\text { amplification }\end{array}$ & $P$ value $^{\mathrm{a}}$ & $0 / 1+$ & $2+/ 3+$ & $P$ value ${ }^{a}$ & $\begin{array}{l}\text { HER2 gene } \\
\text { amplification }\end{array}$ & $\begin{array}{l}\text { No HER2 gene } \\
\text { amplification }\end{array}$ & $P$ value $e^{a}$ \\
\hline \multicolumn{13}{|l|}{ Patient gender } \\
\hline Female & $59(39.9)$ & $20(27.8)$ & NS & $8(25.8)$ & $71(37.6)$ & NS & $69(36.5)$ & $10(32.3)$ & NS & $8(27.6)$ & $71(37.2)$ & NS \\
\hline Male & $89(60.1)$ & $52(72.2)$ & & $23(74.2)$ & $118(62.4)$ & & $120(63.5)$ & $21(67.7)$ & & $21(72.4)$ & $120(62.8)$ & \\
\hline \multicolumn{13}{|l|}{ Site of primary tumour } \\
\hline $\begin{array}{l}\text { Distal oesophagus/ } \\
\text { GOJ/cardia }\end{array}$ & $49(33.1)$ & $34(47.2)$ & NS & $18(58.1)$ & $65(34.4)$ & 0.016 & $69(36.5)$ & $14(45.2)$ & NS & $14(48.3)$ & $69(36.1)$ & NS \\
\hline $\begin{array}{l}\text { Corpus/antrum/ } \\
\text { pylorus }\end{array}$ & $99(66.9)$ & $38(52.8)$ & & $13(41.9)$ & $124(65.6)$ & & $120(63.5)$ & $17(54.8)$ & & $15(51.7)$ & $122(63.9)$ & \\
\hline \multicolumn{13}{|c|}{ Histological differentiation grade } \\
\hline Grade I & $23(15.5)$ & $7(9.7)$ & NS & $2(6.5)$ & $28(14.8)$ & NS & $28(14.8)$ & $2(6.5)$ & NS & $2(6.9)$ & $28(14.7)$ & NS \\
\hline Grade II & $71(48.0)$ & $32(44.4)$ & & $17(54.8)$ & $86(45.5)$ & & $83(43.9)$ & $20(64.5)$ & & $18(62.1)$ & $85(44.5)$ & \\
\hline Grade III & $54(36.5)$ & $33(45.8)$ & & $12(38.7)$ & 75 (39.7) & & $78(41.3)$ & $9(29.0)$ & & $9(31.0)$ & $78(40.8)$ & \\
\hline \multicolumn{13}{|l|}{ Postoperative $\mathrm{T}^{\mathrm{b}}$} \\
\hline pT1-pT2 & $54(37.0)$ & $15(21.4)$ & 0.029 & $4(13.31)$ & 65 (34.9) & 0.020 & $63(34.1)$ & $6(19.4)$ & NS & $6(20.7)$ & $63(33.7)$ & NS \\
\hline pT3-pT4 & $92(63.0)$ & 55 (78.6) & & $26(86.7)$ & $121(65.1)$ & & $122(65.9)$ & 25 (80.6) & & $23(79.3)$ & $124(66.3)$ & \\
\hline \multicolumn{13}{|l|}{ Postoperative stage } \\
\hline$|-| \mid$ & $100(67.6)$ & $42(58.3)$ & NS & $14(45.2)$ & $128(67.7)$ & 0.024 & $125(66.1)$ & $17(54.8)$ & NS & $15(51.7)$ & $127(66.5)$ & NS \\
\hline III-IV & 48 (32.4) & $30(41.7)$ & & 17 (54.8) & 61 (32.3) & & 64 (33.9) & $14(45.2)$ & & $14(48.3)$ & 64 (33.5) & \\
\hline
\end{tabular}

Fisher's exact test

${ }^{b} N=216$, the depth of tumour invasion could not be determined for four patients not receiving surgical treatment 

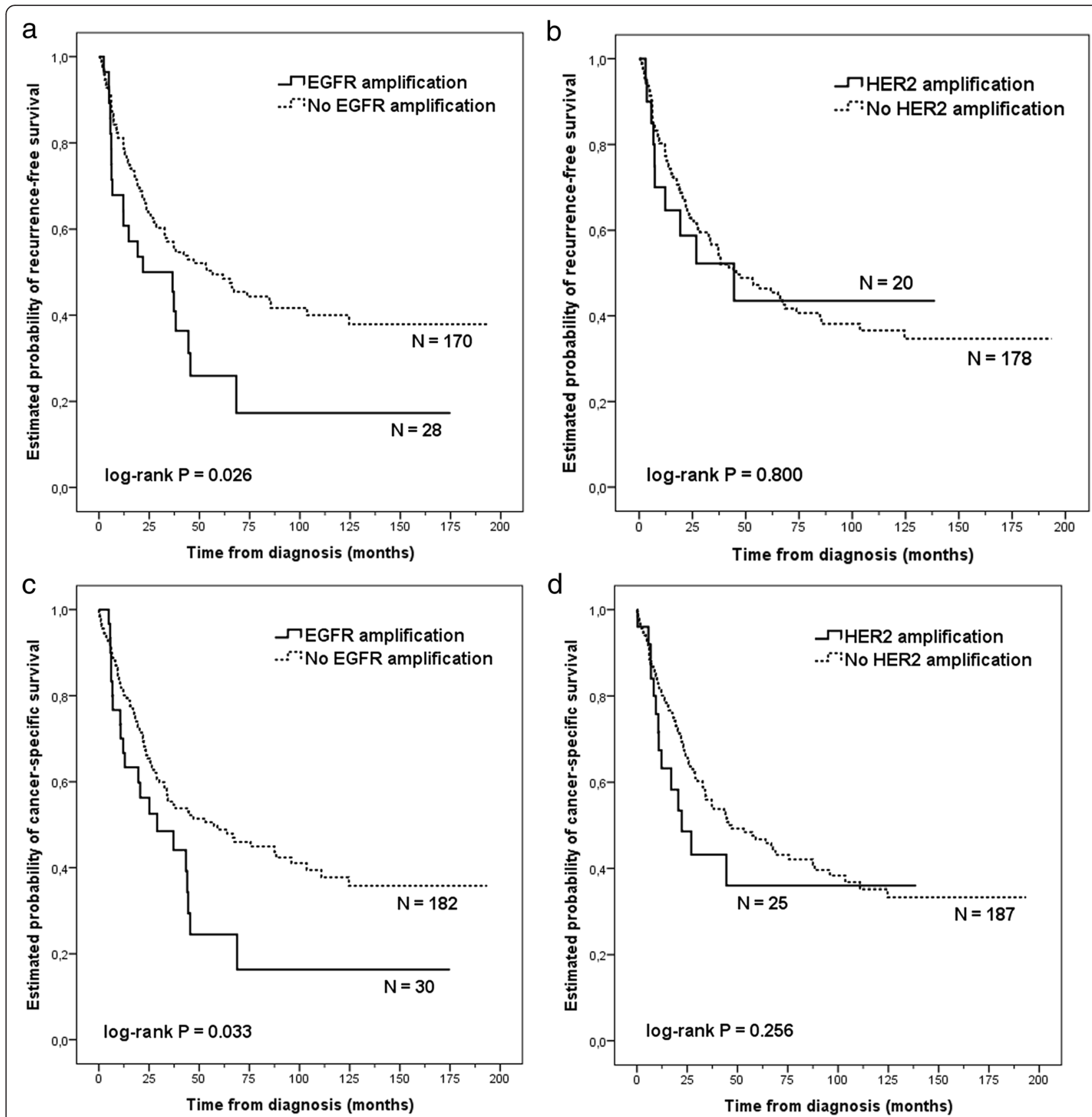

Fig. 3 Kaplan-Meier survival curves of intestinal-type oesophagogastric cancer patients with or without EGFR or HER2 amplification. Time to recurrence $(\mathbf{a}-\mathbf{b})$ and cancer-specific survival $(\mathbf{c}-\mathbf{d})$ as based on EGFR $(\mathbf{a}, \mathbf{c})$ and HER2 (b, d) SISH and IHC analyses. IHC, immunohistochemistry; SISH, silver in situ hybridisation

demonstrated in phase III clinical trials with anti-EGFR antibody treatment in comparison to other chemotherapeutic regimens $[5,6]$. While the EGFR status was not used for patient selection in these earlier studies, an ongoing phase III clinical trial has been reported to select patients based on EGFR overexpression, although defined only by IHC [21]. Overexpression of EGFR protein has been reported in 24-27\% of all gastric adenocarcinomas [14, 16] and in $31 \%$ [14] of intestinal gastric adenocarcinomas. In our study, we found that $32.7 \%$ of the intestinal adenocarcinomas had high EGFR IHC staining intensity, but only 31/ $72(43.1 \%)$ of these demonstrated EGFR gene amplification. This suggests that determining EGFR overexpression of tumours only by IHC, without knowledge of the EGFR GCN, may be an inadequate method for selecting patients for anti-EGFR therapy. Indeed, a recent preclinical study with patient derived xenografts indicated that strongest response to anti-EGFR therapy was achieved in tumours with 
Table 5 Time to recurrence $(T T R)^{a}$ and cancer-specific survival (CSS) ${ }^{b}$ of patients with intestinal-type adenocarcinomas

\begin{tabular}{|c|c|c|c|c|c|c|c|c|c|c|c|c|c|c|c|c|c|c|}
\hline & \multicolumn{6}{|c|}{ Univariate survival analysis for TTR } & \multicolumn{3}{|c|}{$\begin{array}{l}\text { Multivariate survival } \\
\text { analysis for TTR }\end{array}$} & \multicolumn{6}{|c|}{ Univariate survival analysis for CSS } & \multicolumn{3}{|c|}{$\begin{array}{l}\text { Multivariate survival } \\
\text { analysis for CSS }\end{array}$} \\
\hline & $\begin{array}{l}\text { Number } \\
\text { of } \\
\text { patients }\end{array}$ & $\begin{array}{l}\text { TTR, } \\
\text { median } \\
\text { (months) }\end{array}$ & $\begin{array}{l}P \text { value, } \\
\text { log-rank } \\
\text { test }^{c}\end{array}$ & $\begin{array}{l}P \text { value, } \\
\text { Cox test }^{d}\end{array}$ & $\mathrm{HR}$ & $95 \% \mathrm{Cl}$ & $\begin{array}{l}P \text { value, } \\
\text { Cox test }^{b}\end{array}$ & $\mathrm{HR}$ & $95 \% \mathrm{Cl}$ & $\begin{array}{l}\text { Number } \\
\text { of } \\
\text { patients }\end{array}$ & $\begin{array}{l}\text { CSS, } \\
\text { median } \\
\text { (months) }\end{array}$ & $\begin{array}{l}P \text { value, } \\
\text { log-rank } \\
\text { test }^{\mathrm{a}}\end{array}$ & $\begin{array}{l}P \text { value, } \\
\text { Cox test }\end{array}$ & $\mathrm{HR}$ & $95 \% \mathrm{Cl}$ & $\begin{array}{l}P \text { value, } \\
\text { Cox test }^{b}\end{array}$ & $\mathrm{HR}$ & $95 \% \mathrm{Cl}$ \\
\hline Age (continuous variable) & 198 & & & NS & & & & & & 212 & & & 0.048 & 1.02 & $1.00-1.04$ & NS & & \\
\hline \multicolumn{19}{|l|}{ Patient gender } \\
\hline Female (reference) & 71 & 56.6 & NS & NS & & & & & & 78 & 45.6 & NS & NS & & & & & \\
\hline Male & 127 & 38.2 & & & & & & & & 134 & 44.6 & & & & & & & \\
\hline \multicolumn{19}{|l|}{ Site of primary tumour } \\
\hline $\begin{array}{l}\text { Distal oesophagus/ } \\
\text { GOJ/cardia } \\
\text { (reference) }\end{array}$ & 75 & 28.5 & NS & NS & & & & & & 77 & 34.3 & NS & & & & & & \\
\hline $\begin{array}{l}\text { Corpus/antrum/ } \\
\text { pylorus }\end{array}$ & 123 & 53.6 & & & & & NS & & & 135 & 47.1 & & NS & & & & & \\
\hline \multicolumn{19}{|c|}{ Histological differentiation grade } \\
\hline Grade I (reference) & 30 & NA & NS & & & & & & & 30 & NA & NS & & & & & & \\
\hline Grade II & 92 & 33.8 & & 0.043 & 1.95 & $1.02-3.74$ & NS & & & 98 & 33.8 & & 0.020 & 2.22 & $1.13-4.36$ & NS & & \\
\hline Grade III & 76 & 53.2 & & NS & & & NS & & & 84 & 44.6 & & 0.029 & 2.15 & $1.08-4.27$ & NS & & \\
\hline \multicolumn{19}{|l|}{ Postoperative $T$} \\
\hline pT1 (reference) & 37 & 67.3 & $<0.0001$ & & & & & & & 37 & NA & $<0.0001$ & & & & & & \\
\hline pT2 & 31 & NA & & NS & & & & & & 31 & NA & & NS & & & & & \\
\hline pT3 & 75 & 56.6 & & NS & & & & & & 82 & 57.3 & & NS & & & & & \\
\hline pT4 & 55 & 20.5 & & 0.002 & 2.59 & $1.44-4.67$ & & & & 59 & 25.7 & & 0.001 & 2.94 & $1.58-5.47$ & & & \\
\hline \multicolumn{19}{|l|}{ Postoperative stage } \\
\hline I (reference) & 58 & NA & 0.005 & & & & & & & 58 & NA & $<0.0001$ & & & & & & \\
\hline$\|$ & 80 & 38.2 & & NS & & & NS & & & 80 & 57.3 & & NS & & & NS & & \\
\hline III & 60 & 22.6 & & 0.001 & 2.33 & $1.38-3.92$ & 0.014 & 2.05 & $1.16-3.63$ & 60 & 29.0 & & 0.002 & 2.36 & $1.37-4.08$ & 0.023 & 1.99 & $1.10-3.61$ \\
\hline IV & NA & & & & & & & & & 14 & 6.90 & & $<0.0001$ & 14.2 & $6.86-29.3$ & $<0.0001$ & 11.4 & $5.34-24.4$ \\
\hline \multicolumn{19}{|l|}{ EGFR amplification } \\
\hline Yes & 28 & 21.8 & 0.026 & 0.028 & 1.73 & $1.06-2.83$ & NS & & & 30 & 29.0 & 0.033 & 0.035 & 1.67 & $1.04-2.69$ & NS & & \\
\hline No (reference) & 170 & 56.6 & & & & & & & & 182 & 57.3 & & & & & & & \\
\hline
\end{tabular}


Table 5 Time to recurrence (TTR) and cancer-specific survival (CSS) ${ }^{\mathrm{b}}$ of patients with intestinal-type adenocarcinomas (Continued)

HER2 amplification

Yes $20 \quad 44.6$

NS

NS

$25 \quad 22.3$

NS

NS

No (reference)

$178 \quad 45.6$

187

45.6

NS not significant, NA not applicable

${ }^{a}$ Excluding trastuzumab-treated and stage IV patients

Excluding trastuzumab-treated patients

'Kaplan-Meier method

${ }^{d}$ Cox's proportional hazards regression model 
EGFR gene amplification [22]. The relatively low prevalence of co-amplification of EGFR and HER2 genes (3.6 \% in this study) demonstrates the presence of two distinct subgroups of patients with either EGFR or HER2 gene amplification, which implies that anti-EGFR therapies might be applicable to some patients not eligible for anti-HER2 treatment. Those patients having receptor co-amplification might even benefit from a dual-acting antibody treatment.

\section{Conclusions}

In this study, we have shown that EGFR gene amplification is relatively common in intestinal adenocarcinomas of the stomach, gastro-oesophageal junction and distal oesophagus and associates with decreased survival. We have also demonstrated that EGFR GCN can be easily analysed by silver in situ hybridisation in diagnostic tumour material and thus could be applied as a routine histopathological diagnostic method. Based on our results, we suggest that determining EGFR gene amplification status in concert with IHC could be used in future clinical trials to identify patients with inverse prognosis and to improve the specificity of patient selection when investigating the possible benefits of anti-EGFR therapies in the treatment of intestinal-type gastro-oesophageal adenocarcinomas.

\begin{abstract}
Abbreviations
Chr-17, chromosome 17; Cl, confidence interval; CIN, chromosomal instability; CSS, cancer-specific survival; EGFR (ERBB1), epidermal growth factor receptor (erb-b2 receptor tyrosine kinase 1); FFPE, formalin-fixed paraffin-embedded; GCN, gene copy number; GOJ, gastro-oesophageal junction; HER2 (ERBB2), human epidermal growth factor receptor 2 (erb-b2 receptor tyrosine kinase 2); HR, hazard ratio; IHC, immunohistochemistry; MSS, microsatellite stable; NA, not applicable; NS, not significant; OR, odds ratio; OS, overall survival; pT, pathologic T, describes tumour size and depth of invasion; RAS, rat sarcoma viral oncogene homolog; SISH, silver in situ hybridization; TP53, tumour protein $\mathrm{p} 53$; TTR, time to recurrence.
\end{abstract}

\section{Acknowledgements}

We thank Ms Susanna Hussi, Ms Jaana Nurminen and Ms Katja Tamminen for collecting the archived FFPE samples, Ms Sinikka Kollanus and Ms Paula Merilahti for preparing the tissue sections for IHC and SISH and Mr Jaakko Liippo for help with the pictures.

\section{Funding}

This study was supported by the Turku University Foundation, the Cancer Society of Southwest Finland and the Special Government Funding (EVO) allocated to Turku University Hospital. The funders had no role in study design, data collection, analysis and interpretation, decision to publish or preparation of the manuscript.

\section{Availability of data and materials}

All supporting data for the conclusions are included within the article.

\section{Authors' contributions}

EB collected the clinicopathological data, contributed to the histological and molecular analysis, performed the statistical analysis, contributed to data

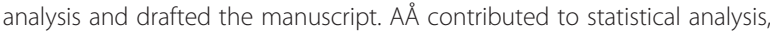
clinical interpretation and manuscript preparation. ML coordinated the molecular testing and contributed to data analysis and manuscript preparation. RR contributed to the collection of clinical data, clinical interpretation and manuscript preparation. JS coordinated the sample choice and provision, verified the histological analysis and contributed to the molecular analysis and manuscript preparation. OC contributed to the overall study design, data interpretation and manuscript preparation. All authors have read and approved the final manuscript.

\section{Competing interests}

$A \AA, M L, R S, J S$ and $O C$ are inventors in a patent related to this work: US 20110217296 A1 Method for selecting patients for treatment with an EGFR inhibitor. Å has had an advisory role with Lilly. All remaining authors declare that they have no competing interests.

\section{Consent for publication}

Not applicable.

\section{Ethics approval and consent to participate}

The study was conducted in accordance with the Declaration of Helsinki and the Finnish legislation for the use of archived tissue specimens and associated clinical information. The clinical data were retrieved, and the histological samples were collected and analysed with the endorsement of the National Authority for Medico-Legal Affairs and The Ethics Committee of the Hospital District of Southwest Finland as well as with the permission of Auria Biobank hosting the specimen archive. All the specimens were from Auria biobank, which has obtained its archived diagnostic sample collection with an opt-out procedure according to the Finnish biobank act. Biobanks authorized and inspected by National Supervisory Authority for Welfare and Health can provide human specimens collected during diagnostic procedures and associated clinical information for research purposes based on the biobank's scientific board review. Thus, informed consent from surviving patients was not required.

\section{Author details}

'Department of Pathology, University of Turku and Turku University Hospital, TYKS-SAPA, Turku, Finland. ${ }^{2}$ Department of Oncology, University of Turku and Turku University Hospital, Turku, Finland. ${ }^{3}$ MediCity Research Laboratory, University of Turku, Turku, Finland. ${ }^{4}$ Auria Biobank, Turku, Finland.

Received: 27 October 2015 Accepted: 23 June 2016

Published online: 07 July 2016

\section{References}

1. Lauren P. The two histological main types of gastric carcinoma: diffuse and so-called intestinal-type carcinoma. An attempt at a histo-clinical classification. Acta Pathol Microbiol Scand. 1965;64:31-49.

2. Cancer Genome Atlas Research Network. Comprehensive molecular characterization of gastric adenocarcinoma. Nature. 2014;513:202-9.

3. Bokemeyer C, Bondarenko I, Makhson A, Hartmann JT, Aparicio J, De Braud F, Donea S, Ludwig H, Schuch G, Stroh C, et al. Fluorouracil, leucovorin, and oxaliplatin with and without cetuximab in the first-line treatment of metastatic colorectal cancer. J Clin Oncol. 2009;27:663-71.

4. Douillard J-Y, Siena S, Cassidy J, Tabernero J, Burkes R, Barugel M, Humblet Y, Bodoky G, Cunningham D, Jassem J, et al. Randomized, Phase III trial of panitumumab with infusional fluorouracil, leucovorin, and oxaliplatin (FOLFOX4) Versus FOLFOX4 alone as first-line treatment in patients with previously untreated metastatic colorectal cancer: The PRIME study. J Clin Oncol. 2010;28:4697-705.

5. Lordick F, Kang Y-K, Chung H-C, Salman P, Oh SC, Bodoky G, Kurteva G, Volovat C, Moiseyenko VM, Gorbunova V, et al. Capecitabine and cisplatin with or without cetuximab for patients with previously untreated advanced gastric cancer (EXPAND): A randomised, open-label phase 3 trial. Lancet Oncol. 2013;14:490-9.

6. Waddell T, Chau I, Cunningham D, Gonzalez D, Frances A, Okines C, Wotherspoon A, Saffery C, Middleton G, Wadsley J, et al. Epirubicin, oxaliplatin, and capecitabine with or without panitumumab for patients with previously untreated advanced oesophagogastric cancer (REAL3): A randomised, open-label phase 3 trial. Lancet Oncol. 2013;14:481-9.

7. Ålgars $\mathrm{A}$, Lintunen $\mathrm{M}$, Carpén O, Ristamäki R, Sundström J. EGFR gene copy number assessment from areas with highest EGFR expression predicts response to anti-EGFR therapy in colorectal cancer. $\mathrm{Br} J$ Cancer. 2011;105:255-62.

8. Ålgars A, Avoranta T, Österlund P, Lintunen M, Sundström J, Jokilehto T, Ristimäki A, Ristamäki R, Carpén O. Heterogeneous EGFR gene copy number increase is common in colorectal cancer and defines response to anti-EGFR therapy. PLoS One. 2014;9(6):e99590. 
9. Bosman F, Carneiro F, Hruban R, Theise N, editors. WHO Classification of Tumours of the Digestive System. 4th ed. Lyon: IARC Press; 2010.

10. Finlex Data Bank. https:/www.finlex.fi/fi/laki/kaannokset/2012/en20120688. pdf. Accessed 26 October 2015

11. Hofmann M, Stoss O, Shi D, Büttner R, Van De Vijver M, Kim W, Ochiai A, Rüschoff J, Henkel T. Assessment of a HER2 scoring system for gastric cancer: Results from a validation study. Histopathology. 2008;52:797-805.

12. Bang Y-J, Van Cutsem E, Feyereislova A, Chung HC, Shen L, Sawaki A, Lordick F, Ohtsu A, Omuro Y, Satoh T, et al. Trastuzumab in combination with chemotherapy versus chemotherapy alone for treatment of HER2positive advanced gastric or gastro-oesophageal junction cancer (ToGA): A phase 3, open-label, randomised controlled trial. Lancet. 2010;376:687-97.

13. Grogan TM, McElhinny AS, Loftin IR, Warren SL, Sugarman M, Miller R, Olivas-Brochu E, Roche P, Walk E, Padilla M, et al. Interpretation Guide. Ventana INFORM HER2 Dual ISH DNA Probe Cocktail Assay. 2010. http:// www.uclad.com/newsletters/HER2_DDISH_Interpretation_Guide.pdf. Accessed 4 July 2016.

14. Kim MA, Lee HS, Lee HE, Jeon YK, Yang HK, Kim WH. EGFR in gastric carcinomas: Prognostic significance of protein overexpression and high gene copy number. Histopathology. 2008;52:738-46.

15. Kandel C, Leclair F, Bou-Hanna C, Laboisse CL, Mosnier J-F. Association of HER1 amplification with poor prognosis in well differentiated gastric carcinomas. J Clin Pathol. 2014;67:307-12.

16. Nagatsuma AK, Aizawa M, Kuwata T, Doi T, Ohtsu A, Fujii H, Ochiai A. Expression profiles of HER2, EGFR, MET and FGFR2 in a large cohort of patients with gastric adenocarcinoma. Gastric Cancer. 2015;18:227-38

17. Tanner M, Hollmén M, Junttila TT, Kapanen Al, Tommola S, Soini Y, Helin H, Salo J, Joensuu H, Sihvo E, et al. Amplification of HER-2 in gastric carcinoma: Association with Topoisomerase lla gene amplification, intestinal type, poor prognosis and sensitivity to trastuzumab. Ann Oncol. 2005;16:273-8.

18. Takehana T, Kunitomo K, Kono K, Kitahara F, lizuka H, Matsumoto Y, Fujino MA, Ooi A. Status of c-erbB- 2 in gastric adenocarcinoma: a comparative study of immunohistochemistry, fluorescence in situ hybridization and enzyme-linked immuno-sorbent assay. Int J Cancer. 2002;98:833-7.

19. Gravalos C, Jimeno A. HER2 in gastric cancer: A new prognostic factor and a novel therapeutic target. Ann Oncol. 2008;19:1523-9.

20. Cristescu R, Nebozhyn M, Kim K-M, Ting J, Wong S, Liu J, Yue Y, Wang J, Yu $\mathrm{K}, \mathrm{Ye} \mathrm{X}$, et al. Molecular analysis of gastric cancer identifies subtypes associated with distinct clinical outcomes. Nat Med. 2015;21:449-56.

21. Kuhnil Pharmaceutical Co. L. Phase 3 Study of Nimotuzumab and Irinotecan as Second Line With Advanced or Recurrect Gastric and Gastroesophageal Junction Cancer. Bethesda: National Library of Medicine; 2013. https:// clinicaltrials.gov/ct2/show/NCT01813253. Accessed 08 Oct 2015.

22. Zhang L, Yang J, Cai J, Song X, Deng J, Huang X, Chen D, Yang M, Wery J-P, Li S, et al. A subset of gastric cancers with EGFR amplification and overexpression respond to cetuximab therapy. Sci Rep. 2013;3:2992.

\section{Submit your next manuscript to BioMed Central and we will help you at every step:}

- We accept pre-submission inquiries

- Our selector tool helps you to find the most relevant journal

- We provide round the clock customer support

- Convenient online submission

- Thorough peer review

- Inclusion in PubMed and all major indexing services

- Maximum visibility for your research

Submit your manuscript at www.biomedcentral.com/submit
Biomed Central 